\title{
CLINICAL PROFILE OF NAFLD PATIENTS AND ITS CORRELATION WITH METABOLIC SYNDROME
}

\author{
Pradeep Nigam1, Ravi Prakash Pandey2, Meghna Pawar3, Manoj Indurkar4
}

${ }^{1}$ Associate Professor, Department of Medicine, SSMC and SGMH, Rewa, Madhya Pradesh.

${ }^{2}$ Assistant Professor, Department of Medicine, SSMC and SGMH, Rewa, Madhya Pradesh.

3 Junior Resident, Department of Medicine, SSMC and SGMH, Rewa, Madhya Pradesh.

${ }^{4}$ Professor and HOD, Department of Medicine, SSMC and SGMH, Rewa, Madhya Pradesh.

\section{BACKGROUND}

ABSTRACT

Non-alcoholic fatty liver disease (NAFLD) is a clinico-pathological entity, increasingly recognised as a major health burden in developed countries and the fastest rising form of chronic liver disease worldwide. It is gaining concern among physicians in developing countries as well as it is predicted that its prevalence may surpass that of chronic hepatitis. It includes a spectrum of liver damage ranging from simple steatosis to non-alcoholic steatohepatitis (NASH), advanced fibrosis and rarely progression to cirrhosis.

\section{MATERIALS AND METHODS}

This was a descriptive study conducted in Department of Medicine, SSMC and SGMH, Rewa. A total of 200 cases were included in the study, who were diagnosed as having fatty liver on the basis of ultrasonography (USG) during the study period of April 2016 to July 2017 and were further investigated for metabolic syndrome.

\section{RESULTS}

Out of 200 cases, 55.5\%, 36\% and 8.5\% of cases had grade I, II and III fatty liver respectively. 128 (64\%) had metabolic syndrome. $63.93 \%, 61.11 \%$ and $76.84 \%$ of grade I, II and III NAFLD patients suffered from metabolic syndrome respectively. All the components of metabolic syndrome were significantly associated with NAFLD ( $\mathrm{p} \leq 0.05)$.

\section{CONCLUSION}

There is higher prevalence of all the components of metabolic syndrome in cases of NAFLD. Signs and symptoms are subtle and occur later in the course of the disease; hence, the physician should have a high index of suspicion in order to detect NAFLD early in the course of the disease. Early detection will help in modifying the disease course and delaying its complications.

\section{KEYWORDS}

Non-Alcoholic Fatty Liver Disease, Metabolic Syndrome, Cardiovascular Disease, Diabetes Mellitus.

HOW TO CITE THIS ARTICLE: Nigam P, Pandey RP, Pawar M, et al. Clinical profile of NAFLD patients and its correlation with metabolic syndrome. J. Evolution Med. Dent. Sci. 2018;7(04):433-436, DOI: 10.14260/jemds/2018/96

\section{BACKGROUND}

NAFLD is defined as the presence of fat in the liver (hepatic steatosis) either on the imaging or on liver histology in individuals who do not consume significant amounts of alcohol $(<20 \mathrm{~g} \text { ethanol/d })^{1}$ and also after the exclusion of secondary causes of fat accumulation in the liver. NAFLD is further categorised histologically into non-alcoholic fatty liver (NAFL) and non-alcoholic steatohepatitis (NASH). NAFL is defined as hepatic steatosis with no evidence of hepatocellular injury in the form of hepatocyte ballooning. Non-alcoholic steatohepatitis is defined as the presence of hepatic steatosis and inflammation with hepatocytic injury (ballooning) with or without fibrosis.

Prevalence of NAFLD in western population is around $15 \%-40 \%$, while in Asian population it is $9 \%-40 \% .^{2-4}$ In India too, NAFLD is emerging as an important cause of liver disease.

'Financial or Other Competing Interest': None.

Submission 07-12-2017, Peer Review 05-01-2018,

Acceptance 11-01-2018, Published 22-01-2018.

Corresponding Author:

Dr. Ravi Prakash Pandey,

F-12, Doctor's Colony,

Medical College Campus,

Rewa-486001, Madhya Pradesh.

E-mail: drraviprakashpandey@gmail.com

DOI: $10.14260 /$ jemds/2018/96

(c) (i) $(9)$
In India prevalence of NAFLD is $9 \%-32 \%$ and higher incidence is seen among diabetic and obese patients. ${ }^{5-8}$ The prevalence is rising in recent years due to changes in dietary habits, being more westernised and owing to increase of sedentary lifestyle, thus placing a worry on NAFLD becoming the main cause of liver disease among young adults and children. ${ }^{9}$

Metabolic syndrome and its determining factors like type 2 diabetes (T2DM), central obesity and dyslipidaemia predisposes to NAFLD. NAFLD is strongly associated with T2DM and cardiovascular disease (CVD).

This work was designed to study the clinical and biochemical profile of patients of NAFLD with varying degrees of severity as diagnosed by ultrasonography and evaluate the relationship between the non-alcoholic fatty liver disease and the metabolic syndrome as defined by the modified NCEP ATP III criteria.

\section{MATERIALS AND METHODS}

Type of Study- This was a descriptive study.

\section{Duration of Study}

July 2016 to August 2017.

\section{Place of Study}

Shyam Shah Medical College and Associated SGMH, Rewa, were taken for the study. 
The patient diagnosed as NAFLD on USG seeking treatment in the Department of Medicine IPD and OPD were included and investigated for metabolic syndrome according to the NCEP ATP III criteria. The data was collected during OPD/ IPD treatment and was recorded in predesigned and pretested proforma and analysed.

\section{The Study Subjects were in the Age Group of 18 - 65} Years

1. Detailed history including that of alcohol consumption was taken after informed consent.

2. Anthropometric measurements like weight, height, Body Mass Index (BMI) and waist-hip ratio was measured.

3. Biochemical tests such as fasting blood glucose, postprandial blood glucose, glycosylated haemoglobin, fasting lipid profile and liver function tests were done.

4. USG abdomen.

\section{Inclusion Criteria}

1. Non-alcoholic individuals with age $>18$ years, defined as either total abstainers or who consumed $<20 \mathrm{~g}$ of alcohol per day (confirmed by two family members).

2. Ultrasound showing hyperechoic liver suggestive of fatty liver according to standard criteria accepted by the American Gastroenterology Association. ${ }^{10}$

Grade 1: Slight diffuse increase in the fine echoes. Liver appears bright as compared to the cortex of the kidney. Normal visualisation of the diaphragm and intrahepatic vessel borders.

Grade 2: Moderate diffuse increase in the fine echoes. Slightly impaired visualisation of the intrahepatic vessels and diaphragm.

Grade 3: Marked increase in the fine echoes. Poor or no visualisation of intrahepatic vessel borders, diaphragm and the vessels.

\section{Exclusion Criteria}

1. Positive hepatitis B surface antigen (HBsAg) and antibodies to hepatitis $\mathrm{C}$ virus (anti-HCV).

2. Positive autoimmune markers (anti-nuclear antibody, anti-smooth muscle antibody, anti-liver kidney microsomal antibody, anti-mitochondrial antibody).

3. Low ceruloplasmin level/ positive Kayser-Fleischer rings.

4. Abnormal iron work-up (high serum iron, low total iron binding capacity, high ferritin or transferrin saturation).

5. Use of drugs such as amiodarone, corticosteroids, tamoxifen, methotrexate or high-dose oestrogens.

6. Patients on total parenteral nutrition.

\section{Statistical Analysis}

Data was collected and analysed to assess the categorical data presented as numbers and percentages. $\mathrm{P}$ value of 0.05 or less was considered statistically significant.

\section{RESULTS}

Total of 200 cases ultrasonographically diagnosed as NAFLD were enrolled in our study and it was observed that 55.5\%, $36 \%$ and $8.5 \%$ of cases had grade I, II and III fatty liver respectively.

Mean age of the patients was $48.9 \pm 9.21$ years with peak in fifth decade of life. Male-to-female ratio was 2:3. Abdominal pain was the presenting symptom in $36.5 \%$ of the patients followed by easy fatiguability in $29.68 \%$. Clinical and biochemical parameter of all the cases of NAFLD are described in Table I.

Out of all the NAFLD patients, 128 (64\%) had metabolic syndrome as per NCEP ATP III criteria using Asian-Indian criteria for waist circumference, $63.93 \%, 61.11 \%$ and $76.48 \%$ of grade I, II and III NAFLD patients suffered from metabolic syndrome respectively (Table IV). All components of metabolic syndrome was significantly associated with NAFLD $(\mathrm{p} \leq 0.05)$ (Table II).

$82(41 \%)$ of total patients were hypertensive (Graph I). Percentage of hypertensive patients increased as grade of NAFLD increased in patients with metabolic syndrome i.e. $32.39 \%, 50 \%$ and $61.53 \%$ in grade I, II and III respectively (Table V). The mean BMI of the patients was $27.31 \pm 4.8$ $\mathrm{kg} / \mathrm{m}^{2}, 6.5 \%$ (13) of patients were having normal BMI, $62 \%$ and $31.5 \%$ were overweight and obese respectively. While 118 (59\%) patients had increased waist circumference (Graph I).

Diabetics were $58.5 \%$ (117) of total patients (Graph I), out of which $90(76.92 \%)$ patients were associated with NAFLD with Metabolic syndrome as compared to 27 (23.07\%) patients of NAFLD without metabolic syndrome and the difference was statistically significant (Table V). Among the NAFLD with Metabolic syndrome (90 patients), maximum patients were having grade II fatty liver disease followed by grade I and grade III. ALT and AST levels were elevated in $50.5 \%$ and $32.5 \%$ of patients and AST/ALT ratio was $<1.0$ in $95 \%$ of the patients.

Hypertriglyceridaemia was seen in $68.5 \%$ (137) patients (Graph I). $82.03 \%$ patients of fatty liver with metabolic syndrome had hypertriglyceridaemia (Table II), 88.63\% that is maximum patients with grade II fatty liver with metabolic syndrome had hypertriglyceridaemia (Table V). Low serum HDL level were seen in 49\% (98) patients (Table II).

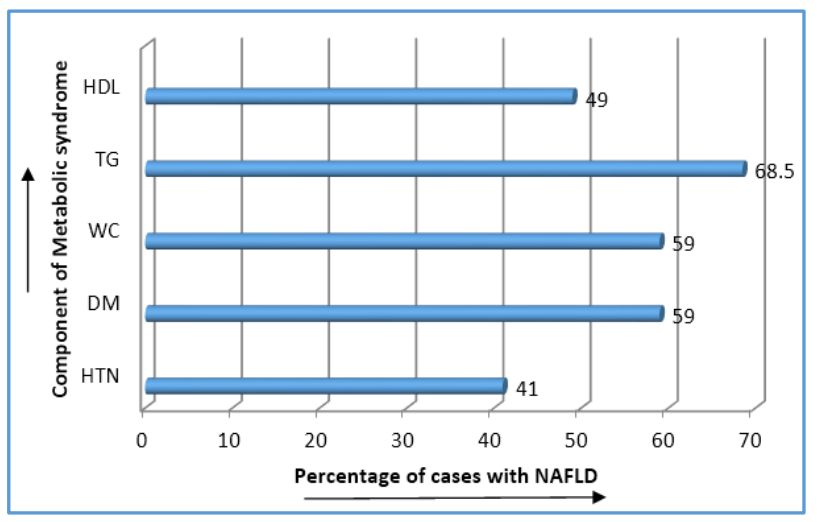

Graph I. Showing Prevalence of various Components of Metabolic Syndrome in NAFLD 


\begin{tabular}{|c|c|c|}
\hline Variable & Mean & ISD \\
\hline Age (in year) & 48.99 & \pm 9.21 \\
\hline Body Mass Index $\left(\mathrm{kg} / \mathrm{m}^{2}\right)$ & 27.31 & \pm 4.81 \\
\hline Waist Circumference (cm) & 86.23 & \pm 15.49 \\
\hline Systolic Blood Pressure (mmHg) & 131.81 & \pm 26.69 \\
\hline Diastolic Blood Pressure (mmHg) & 80.10 & \pm 10.64 \\
\hline Fasting Blood Sugar (mg/dL) & 110.6 & \pm 41.52 \\
\hline Serum Triglycerides (mg/dL) & 173.18 & \pm 56.60 \\
\hline High Density Lipoprotein & 44.58 & \pm 9.72 \\
\hline (mg/dL) & 40.23 & \pm 24.08 \\
\hline Aspartate Aminotransferase (IU) & 54.16 & \pm 28.80 \\
\hline Alanine Aminotransferase (IU) & Table I. Clinical and Biochemical Profile of all the Patients \\
\hline \multicolumn{2}{|c|}{ with NAFLD (n= 200) } \\
\hline
\end{tabular}

\begin{tabular}{|c|c|c|c|}
\hline Variable & $\begin{array}{c}\text { NAFLD* with } \\
\text { Metabolic } \\
\text { Syndrome } \\
\text { (n=128) } \\
\text { No. } \%\end{array}$ & $\begin{array}{c}\text { NAFLD } \\
\text { without } \\
\text { Metabolic } \\
\text { Syndrome } \\
\text { (n=72) } \\
\text { No. } \%\end{array}$ & P value \\
\hline $\begin{array}{c}\text { Fasting Plasma } \\
\text { Glucose }>100 \\
\text { mg/dL }\end{array}$ & $90(70.31 \%)$ & $27(38.89 \%)$ & $<0.005$ \\
\hline $\begin{array}{c}\text { Hypertension } \\
>130 / 85 \mathrm{mmHg}\end{array}$ & $53(41.4 \%)$ & $29(40.27 \%)$ & $<0.005$ \\
\hline $\begin{array}{c}\text { Waist } \\
\text { Circumference } \\
\mathrm{M}>90 \mathrm{~cm} \text { F }>80 \\
\mathrm{~cm}\end{array}$ & $93(72.65 \%)$ & $25(34.72 \%)$ & $<0.005$ \\
\hline $\begin{array}{c}\text { Triglycerides } \\
>150 \mathrm{mg} / \mathrm{dL}\end{array}$ & $105(82.03 \%)$ & $32(44.4 \%)$ & $<0.005$ \\
\hline \multicolumn{2}{|c|}{$\mathrm{HDL}$} \\
$\begin{array}{c}\mathrm{M}<50 \mathrm{mg} / \mathrm{dL} \\
\mathrm{F}<40 \mathrm{mg} / \mathrm{dL}\end{array}$ & $77(60.15 \%)$ & $21(29.16 \%)$ & $<0.005$ \\
\hline $\begin{array}{c}\text { Table II. Comparison of Prevalence of variable in Patients } \\
\text { of NAFLD with Metabolic Syndrome and NAFLD without } \\
\text { Metabolic Syndrome }\end{array}$ & \\
\hline
\end{tabular}

NAFLD- Non-Alcoholic Fatty Liver Disease.

\begin{tabular}{|c|c|c|c|}
\hline Variable & $\begin{array}{l}\text { NAFLD with } \\
\text { Metabolic } \\
\text { Syndrome } \\
(\mathbf{n}=128)\end{array}$ & $\begin{array}{c}\text { NAFLD } \\
\text { without } \\
\text { Metabolic } \\
\text { Syndrome } \\
(n=72)\end{array}$ & P value \\
\hline $\begin{array}{c}\text { Fasting Plasma } \\
\text { glucose }>100 \\
\mathrm{mg} / \mathrm{dL}\end{array}$ & $149 \pm 50.02$ & $110 \pm 41.52$ & $<0.0001$ \\
\hline $\begin{array}{c}\text { Hypertension } \\
>130 / 85 \mathrm{mmHg}\end{array}$ & $149 \pm 42.24$ & $131 \pm 26.69$ & $<0.0001$ \\
\hline $\begin{array}{c}\text { Waist } \\
\text { Circumference } \\
\mathrm{M}>90 \mathrm{~cm} \mathrm{~F}>80 \\
\mathrm{~cm}\end{array}$ & $101 \pm 44.3$ & $86.23 \pm 15.49$ & $<0.0001$ \\
\hline $\begin{array}{c}\text { Triglycerides } \\
>150 \mathrm{mg} / \mathrm{dL}\end{array}$ & $195 \pm 43.01$ & $173 \pm 56.60$ & $<0.0001$ \\
\hline $\begin{array}{c}\text { HDL } \mathrm{M}<50 \\
\mathrm{mg} / \mathrm{dL} \\
\mathrm{F}<40 \mathrm{mg} / \mathrm{dL}\end{array}$ & $32 \pm 5.67$ & $44 \pm 9.72$ & $<0.0001$ \\
\hline \multicolumn{4}{|c|}{$\begin{array}{l}\text { Table III. Comparison of Means of all the Components of } \\
\text { Metabolic Syndrome in Patients of NAFLD with and } \\
\text { without Metabolic Syndrome }\end{array}$} \\
\hline
\end{tabular}

NAFLD- Non-Alcoholic Fatty Liver Disease.

\begin{tabular}{|c|c|c|c|}
\hline $\begin{array}{c}\text { Metabolic } \\
\text { Syndrome }\end{array}$ & $\begin{array}{c}\text { Grade I NAFLD* } \\
\text { (n=111) }\end{array}$ & $\begin{array}{c}\text { Grade II NAFLD } \\
\text { (n=72) }\end{array}$ & $\begin{array}{c}\text { Grade III } \\
\text { NAFLD (n=17) }\end{array}$ \\
\hline Present & $71(63.93 \%)$ & $44(61.11 \%)$ & $13(76.48 \%)$ \\
\hline Absent & $40(36.04 \%)$ & $28(38.89 \%)$ & $04(23.52 \%)$ \\
\hline Table IV. Distribution of Prevalence of Metabolic Syndrome \\
in different Grades of Fatty Liver \\
\hline
\end{tabular}

\begin{tabular}{|c|c|c|c|c|c|c|}
\hline \multirow{3}{*}{ Variables } & \multirow{2}{*}{\multicolumn{2}{|c|}{$\begin{array}{c}\text { Grade I NAFLD } \\
*(n=111) \\
\text { Metabolic } \\
\text { Syndrome } \\
\text { Yes/No }\end{array}$}} & \multirow{2}{*}{\multicolumn{2}{|c|}{$\begin{array}{c}\begin{array}{c}\text { Grade II NAFLD } \\
(\mathrm{n}=72)\end{array} \\
\text { Metabolic } \\
\text { Syndrome } \\
\text { Yes/No }\end{array}$}} & \multirow{2}{*}{\multicolumn{2}{|c|}{\begin{tabular}{|c|}
$\begin{array}{c}\text { Grade III NAFLD } \\
\text { (n=17) }\end{array}$ \\
Metabolic \\
Syndrome \\
Yes/No
\end{tabular}}} \\
\hline & & & & & & \\
\hline & (71) & $(40)$ & (44) & (28) & & \\
\hline $\begin{array}{c}\text { AST }^{+} \\
>38 \mathrm{IU}\end{array}$ & $\begin{array}{c}19 \\
(26.76 \%)\end{array}$ & $\begin{array}{c}14 \\
(32.81 \%)\end{array}$ & $\begin{array}{c}16 \\
(36.36 \%)\end{array}$ & $\begin{array}{c}07 \\
(25 \%)\end{array}$ & $\begin{array}{c}07 \\
(53.84 \%)\end{array}$ & $\begin{array}{c}02 \\
(50 \%) \\
\end{array}$ \\
\hline $\begin{array}{c}\text { ALT } \\
*>41 \mathrm{IU} \\
\end{array}$ & $\begin{array}{c}28 \\
(39.43 \%) \\
\end{array}$ & $\begin{array}{c}18 \\
(45 \%) \\
\end{array}$ & $\begin{array}{c}29 \\
(65.09 \%) \\
\end{array}$ & $\begin{array}{c}14 \\
(50 \%) \\
\end{array}$ & $\begin{array}{c}09 \\
(69.23 \%) \\
\end{array}$ & $\begin{array}{c}03 \\
(75 \%) \\
\end{array}$ \\
\hline $\begin{array}{c}\text { Fasting } \\
\text { blood Suggar } \\
\text { level }>100 \\
\mathrm{mg} / \mathrm{dL}\end{array}$ & $\begin{array}{c}45 \\
(63.38 \%)\end{array}$ & $\begin{array}{c}13 \\
(32.5 \%)\end{array}$ & $\begin{array}{c}38 \\
(86.36 \%)\end{array}$ & $\begin{array}{c}12 \\
(42.86 \%\end{array}$ & $\begin{array}{c}07 \\
(53.85 \%)\end{array}$ & $\begin{array}{c}02 \\
(50 \%)\end{array}$ \\
\hline $\begin{array}{c}\text { Hyper- } \\
\text { tension } \\
>130 / 85 \\
\text { mmHg } \\
\end{array}$ & $\begin{array}{c}23 \\
(32.39 \%)\end{array}$ & $\begin{array}{c}15 \\
(37.5 \%)\end{array}$ & $\begin{array}{c}22 \\
(50 \%)\end{array}$ & $\begin{array}{c}12 \\
(42.86 \%)\end{array}$ & $\begin{array}{c}08 \\
(61.53 \%)\end{array}$ & $\begin{array}{c}2 \\
(50 \%)\end{array}$ \\
\hline \begin{tabular}{|c|} 
Waist \\
Circum- \\
ference \\
$\mathrm{M}>90 \mathrm{~cm}$ \\
$\mathrm{~F}>80 \mathrm{~cm}$ \\
\end{tabular} & $\begin{array}{c}52 \\
(73.23 \%)\end{array}$ & $\begin{array}{c}14 \\
(35 \%)\end{array}$ & $\begin{array}{c}32 \\
(72.72 \%)\end{array}$ & $\begin{array}{c}09 \\
(32.14 \%)\end{array}$ & $\begin{array}{c}09 \\
(69.23 \%)\end{array}$ & $\begin{array}{c}02 \\
(50 \%)\end{array}$ \\
\hline $\begin{array}{l}\text { Hypertriglyc } \\
\text { eridemia } \\
>150 \mathrm{mg} / \mathrm{dL}\end{array}$ & $\begin{array}{c}56 \\
(78.87 \%)\end{array}$ & $\begin{array}{c}21 \\
(52.5 \%)\end{array}$ & $\begin{array}{c}39 \\
(88.63 \%)\end{array}$ & $\begin{array}{c}10 \\
(35.71 \%)\end{array}$ & $\left(\begin{array}{c}10 \\
(76.92 \%)\end{array}\right.$ & $\begin{array}{c}01 \\
(25 \%)\end{array}$ \\
\hline $\begin{array}{l}\text { Low HDL } \\
\mathrm{M}<40 \mathrm{mg} / \mathrm{dL} \\
\mathrm{F}<50 \mathrm{mg} / \mathrm{dL}\end{array}$ & $\begin{array}{c}39 \\
(54.92 \%)\end{array}$ & $\begin{array}{c}11 \\
(27.5 \%)\end{array}$ & $\begin{array}{c}30 \\
(68.18 \%)\end{array}$ & $\begin{array}{c}08 \\
(40 \%)\end{array}$ & $\begin{array}{c}08 \\
(61.53 \%)\end{array}$ & $\begin{array}{c}02 \\
(50 \%)\end{array}$ \\
\hline
\end{tabular}

*NAFLD- Non-alcoholic fatty liver disease, ${ }^{+}$Aspartate aminotransferase, ${ }^{* *}$ Alanine aminotransferase, ${ }^{+}{ }_{\text {High density }}$ lipoprotein.

\section{DISCUSSION}

NAFLD has emerged as the most common cause of chronic liver disease worldwide. NAFLD can lead to hepatocellular carcinoma. NAFLD is an independent determinant of cardiovascular disease (CVD). NAFLD is therefore a complex problem with complications far beyond the liver, but there is little information on the association between the metabolic disease and the severity of fatty liver.

Prevalence of NAFLD was higher in female $(60 \%)$ as compared to male (40\%). Gurinder Mohan et al ${ }^{10}$ in his study found that prevalence of NAFLD among females (45\%) was higher when compared to males (32.6\%).

$55 \%, 36 \%$ and $8.5 \%$ of cases had grade I, II and III fatty liver respectively. Pande $\mathrm{A}$ and Pande $\mathrm{V}^{11}$ found in their study that $49 \%, 38 \%$ and $13 \%$ had grade I, II and III fatty liver disease respectively. $64 \%$ (128) of NAFLD cases had metabolic syndrome according to the NCEP ATP III modified criteria using Asian Indian standards for waist circumference. Ajay Duseja et $\mathrm{al}^{5}(50 \%)$ and Deepa Uchil et $\mathrm{al}^{8}(47.1 \%)$ have had similar findings. Majority of patients (76.48\%) having metabolic syndrome had grade III NAFLD, while in those without metabolic syndrome majority $(38.89 \%)$ had grade II NAFLD.

118 (59\%) of those having NAFLD with metabolic syndrome had increased waist circumference (male $>90 \mathrm{cms}$, 
female $>80 \mathrm{cms}$ ) and this observation was statistically significant ( $\mathrm{p}$ value $<0.0001$ ) (Table II). $58.7 \%$ and $47.1 \%$ of cases had increased waist circumference as reported by Ajay Duseja et $\mathrm{a}^{5}$ and Bajaj et al ${ }^{12}$ respectively.

$117(58.5 \%)$ cases had impaired fasting glucose $(>100$ $\mathrm{mg} / \mathrm{dL}$ ) and this observation was statistically significant ( $\mathrm{p}$ value < 0.0001 ). $63.38 \%, 86.36 \%$ and $53.85 \%$ of the patients with grade I, II and III fatty liver disease along with metabolic syndrome had impaired fasting glucose level (Table V). $72.4 \%$ and $28 \%$ patients had impaired fasting glucose as reported by Ajay Duseja et al and Bajaj et al respectively.5,12 $57(28.5 \%)$ patients were having frank diabetes (> 126 $\mathrm{mg} / \mathrm{dL}$ ) as compared to $9 \%$ described by Kaushal et al in those having metabolic syndrome. ${ }^{13}$ International Diabetic Federation states that once the diagnosis of metabolic syndrome is made, the future management of the condition should be aggressive and uncompromising and the aim is to reduce the risk of type II diabetes mellitus and coronary vascular disease.

$41 \%$ patients had blood pressure $\geq 130 / 85 \mathrm{mmHg}$ with a mean of $131.81 \pm 26.69 / 80.10 \pm 10.64 \mathrm{mmHg}$, which was similar to that reported by Bajaj et al (48.72\%). ${ }^{12}$ Percentage of hypertensive patients increased as grade of NAFLD increased in patients with metabolic syndrome.

The presence of an elevated ALT level is often the first clue in the diagnosis of NAFLD. In the majority of patients, the serum ALT level is only increased by 1 - 4 times the upper limits of normal. AST levels may also be minimally elevated. In our study, $32.5 \%$ have elevated AST and $50.5 \%$ have elevated ALT levels. Animesh Deb et $\mathrm{al}^{14}$ found in his study that $45.13 \%$ and $51.18 \%$ of patients had elevated AST and ALT levels. 53.84\% and 69.23\% (AST and ALT) who had grade III fatty liver had metabolic syndrome. $36.36 \%$ and 65.09\% (AST and ALT) who had grade II fatty liver had metabolic syndrome.

In patients of NAFLD with metabolic syndrome 105 (82.03\%) had hypertriglyceridaemia (> $150 \mathrm{mg} / \mathrm{dL}$ ) with a mean of $173.18 \pm 56.60$, which is significantly higher than those reported by Deepa Uchil et al (43.6\%) and Bajaj et al $(23.1 \%) .8,1298$ (49\%) patients had low HDL levels $(<40$ $\mathrm{mg} / \mathrm{dL}$ in males and $<50 \mathrm{mg} / \mathrm{dL}$ in females) with a mean of $44.58 \pm 9.72 \mathrm{mg} / \mathrm{dL}$ as compared to $66.7 \%$ described by Bajaj et al.12 Dyslipidaemia between the two groups, i.e. NAFLD with and without metabolic syndrome was significant ( $p$ value $<0.005$ ).

Thus, the presence of fatty liver correlates significantly with the prevalence and degree of hypertension, abnormal glucose, obesity and dyslipidaemia (Graph I).

\section{CONCLUSION}

NAFLD is an asymptomatic disease, but it is atherogenic and predisposes to diabetes, hypertension and dyslipidaemia. Thus, NAFLD should be considered as the risk factor for ASCVD, and it should be considered early for planning the management of ASCVD. We suggest it should be considered as a sixth component of metabolic syndrome and high prevalence of metabolic syndrome in this NAFLD patients reinforces the need for a comprehensive non-communicable disease prevention and control program. Primary prevention should be started even if fatty liver is being diagnosed incidentally on imaging studies to prevent complications.

\section{REFERENCES}

[1] McCullough AJ. The clinical features, diagnosis and natural history of the nonalcoholic fatty liver disease. Clin Liver Dis 2004;8(3):521-33.

[2] Farrell GC, Larter CZ. Nonalcoholic fatty liver disease: from steatosis to cirrhosis. Hepatology 2006;43(2 Suppl 1):S99-112.

[3] Lazo M, Clark JM. The epidemiology of nonalcoholic fatty liver disease: a global perspective. Semin Liver Dis 2008;28(4):339-50.

[4] Bellentani S, Scaglioni F, Marino M, et al. Epidemiology of non-alcoholic fatty liver disease. Dig Dis 2010;28(1):155-61.

[5] Dusela A. Nonalcoholic fatty liver disease in India-a lot done, yet more required. Indian J Gastroenterol 2010;29(6):217-25.

[6] Gupte P, Amarapurkar D, Agal S, et al. Non-alcoholic steatohepatitis in type 2 diabetes mellitus. J Gastroenterol Hepatol 2004;19(8):854-8.

[7] Amarapurkar D, Kamani P, Patel N, et al. Prevalence of non-alcoholic fatty liver disease: population based study. Ann Hepatol 2007;6(3):161-3.

[8] Uchil D, Pipalia D, Chawla M, et al. Non-alcoholic fatty liver disease (NAFLD)--the hepatic component of metabolic syndrome. J Assoc Physicians India 2009;57:201-4.

[9] Masarone M, Federico A, Abenavoli L, et al. Non alcoholic fatty liver: epidemiology and natural history. Rev Recent Clin Trials 2014;9(3):126-33.

[10] Mohan G, Bhalla N, Kaur R, et al. To study the prevalence of non alcoholic fatty liver disease and its correlation with metabolic syndrome. Journal of Evolution of Medical And Dental Sciences 2013;50:9707-15.

[11] Pande A, Pande V. Clinical profile of patients with nonalcoholic fatty liver disease and its association with metabolic syndrome. Int J Adv Med 2017;4(4).

[12] Bajaj S, Nigam P, Luthra A, et al. A case-control study on insulin resistance, metabolic covariates \& prediction score in non-alcoholic fatty liver disease. Indian J Med Res 2009;129(3):285-92.

[13] Madan K, Batra Y, Gupta SD, et al. Non-alcoholic fatty liver disease may not be a severe disease at presentation among Asian Indians. World J Gastroenterol 2006;12(21):3400-5.

[14] Deb A, Chattopadhyay A, Hassan K, et al. Clinical profile of patients with nonalcoholic fatty liver disease and its association with metabolic syndrome: a crosssectional study. IOSR J Dent Med Sci (IOSR-JDMS) 2015;14(12):11-5. 